\title{
Fluid Replacement Versus Fluid Restriction in COVID-19 Associated Hyponatremia
}

\author{
Adeel A. Khan ${ }^{1}$, Fateen Ata ${ }^{1}$, Waqar Munir ${ }^{2}$, Zohaib Yousaf ${ }^{1,3}$ \\ 1. Internal Medicine, Hamad Medical Corporation, Doha, QAT 2. Infectious Disease, Hamad Medical Corporation, \\ Doha, QAT 3. Clinical Research, Dresden International University, Dresden, DEU
}

Corresponding author: Adeel A. Khan, adeel_1026@yahoo.com

\begin{abstract}
Hyponatremia is one of the most frequently observed electrolyte abnormalities in coronavirus disease 2019 (COVID-19). Literature describes syndrome of inappropriate anti diuretic hormone (SIADH) as the mechanism of hyponatremia in COVID-19 requiring fluid restriction for management. However, it is important to rule out other etiologies of hyponatremia in such cases keeping in mind the effect of an alternate etiology on patient management and outcome. We present a case of hypovolemic hyponatremia in a patient with COVID-19, which unlike SIADH, required fluid replacement early in the disease course for its correction. A 52-year-old Filipino gentleman presented with a three-week history of diarrhea and symptomatic hyponatremia. There was no history of fever or respiratory symptoms. Physical examination revealed a dehydrated and confused middle-aged gentleman. Labs revealed lymphopenia, thrombocytopenia, and severe hyponatremia $(108 \mathrm{mmol} / \mathrm{L})$. Blood cultures and stool workup were negative. Severe acute respiratory syndrome coronavirus 2 (SARS-CoV-2) nasopharyngeal swab was positive. Hyponatremia workup excluded SIADH. The patient had hypovolemic hyponatremia due to gastrointestinal (GI) losses and was managed with saline infusion for correction of hyponatremia with improvement in his clinical status. Hyponatremia in COVID-19 is not only secondary to SIADH but can also be due to other etiologies. Hypovolemic hyponatremia should be distinguished from SIADH as these conditions employ different management strategies, and early diagnosis and management of hypovolemic hyponatremia affects morbidity and mortality.
\end{abstract}

Received 06/29/2020 Review began 07/03/2020 Review ended 07/03/2020 Published 07/08/2020

\section{() Copyright 2020}

Khan et al. This is an open access article distributed under the terms of the Creative Commons Attribution License CC-BY 4.0., which permits unrestricted use, distribution, and reproduction in any medium, provided the original author and source are credited.

Categories: Endocrinology/Diabetes/Metabolism, Internal Medicine, Infectious Disease

Keywords: covid-19, hypovolemia, hyponatremia, inappropriate adh syndrome, sars virus

\section{Introduction}

Hyponatremia has been reported in patients with lower respiratory tract infections and can be hypervolemic, euvolemic, or hypovolemic, with different underlying pathophysiological mechanisms [1]. The severe acute respiratory syndrome coronavirus 2 (SARS-CoV-2) infection has been recently reported to manifest as hyponatremia secondary to syndrome of inappropriate anti diuretic hormone (SIADH ) [2-6]. However, hyponatremia can be due to other etiologies as well. With the prevalence of gastrointestinal (GI) symptoms in coronavirus disease 2019 (COVID-19), there is a possibility of hypovolemic hyponatremia secondary to GI loss [7]. A timely clinical judgment based on etiology guides the management strategy.

\section{Case Presentation}

A 52-year-old Filipino gentleman, known hypertensive, presented with a one-day history of confusion, fatigue, and two episodes of vomiting. This presentation was accompanied by generalized abdominal pain and nonbloody diarrhea of three weeks' duration. There was no history of fever or respiratory symptoms. Vital signs were within normal limits. Physical examination revealed a dehydrated middle-aged gentleman, inconsistently oriented to time, place, and person, with no focal neurological deficit. The rest of the physical examination was unremarkable. Initial labs revealed lymphopenia, thrombocytopenia, and severe hyponatremia $(108 \mathrm{mmol} / \mathrm{L})$. The patient was managed in the medical ICU, where he received hypertonic saline $100 \mathrm{~mL}$ thrice, followed by normal saline infusion of $2 \mathrm{~L}$, with a close serum sodium monitoring.

The initial working diagnosis was of gastroenteritis due to an infectious etiology. Blood and stool workup did not detect any common bacterial, viral, or parasitic pathogen. The SARS-CoV-2 nasopharyngeal swab was sent for polymerase chain reaction (PCR), which came back positive. Apart from fluid replacement, the patient was managed conservatively.

Hyponatremia workup excluded SIADH and was secondary to GI loss (Table 1). Timely determination of the etiology of hyponatremia led to successful but gradual improvement in the symptoms and sodium level. The patient improved and was discharged in a stable condition. 


\section{Cureus}

\begin{tabular}{|c|c|c|}
\hline Investigation & Result & Normal range \\
\hline White blood cell count & 7.8 & $4-10 \times 10^{\wedge} 3 / \mathrm{uL}$ \\
\hline Hemoglobin & 17 & $13-17 \mathrm{~g} / \mathrm{dL}$ \\
\hline Hematocrit & 43.3 & $40 \%-50 \%$ \\
\hline Lymphocyte count & 0.5 & $1-3 \times 10^{\wedge} 3 / \mathrm{uL}$ \\
\hline Platelets & 73 & $150-400 \times 10^{\wedge} 3 / \mathrm{uL}$ \\
\hline Creatinine & 96 & 62-106 umol/L \\
\hline Alanine aminotransferase & 81 & $0-41 \mathrm{UL}$ \\
\hline C-Reactive protein & 52.8 & $0-5 \mathrm{mg} / \mathrm{L}$ \\
\hline Procalcitonin & 0.22 & $<0.5 \mathrm{ng} / \mathrm{mL}$ \\
\hline Lactic acid & 2.3 & $0.5-2.2 \mathrm{mmol} / \mathrm{L}$ \\
\hline SARS-CoV-2 PCR & positive & Not applicable \\
\hline Serum sodium & 108 & 136-145 mmol/L \\
\hline Serum osmolality & 225 & $275-295$ mmol/kg \\
\hline Urine sodium & 36 & $25-40 \mathrm{mEq} / \mathrm{L}$ \\
\hline Urine osmolality & 145 & $150-1150 \mathrm{mmol} / \mathrm{kg}$ \\
\hline TSH & 0.92 & $0.3-4 \mathrm{mlU} / \mathrm{L}$ \\
\hline Serum cortisol level (AM) & 557 & $133-537 \mathrm{mmol} / \mathrm{L}$ \\
\hline
\end{tabular}

TABLE 1: Relevant lab investigations.

SARS-CoV-2 PCR, severe acute respiratory syndrome coronavirus 2 polymerase chain reaction; TSH, thyroid stimulating hormone

\section{Discussion}

COVID-19 is caused by SARS-CoV-2. The mode of transmission is person to person, primarily via respiratory droplets. The most common symptoms are respiratory, but GI symptoms have also been reported [8].

Hyponatremia is associated with COVID-19 [8-9]. Yousaf et al. described the mechanism of hyponatremia in COVID-19 secondary to SIADH as being multifactorial, including increased interleukin-6 (IL-6) levels stimulating antidiuretic hormone (ADH) release [5]. In the case series, all three patients recovered with fluid restriction. However, it is essential to consider other possible etiologies as a cause of hyponatremia in COVID-19.

Measuring the osmolality of serum and urine is essential in the management of hyponatremia. A normal or high serum osmolality would indicate pseudohyponatremia. Once a low serum osmolality affirms the diagnosis of true hyponatremia, urine osmolality is needed to distinguish between SIADH and other causes. Sodium excretion in urine is a marker of the volume status. However, during initial decision making, clinical judgement of volume status is paramount to prevent any delay in treatment. Volume status would be the deciding factor between fluid conservative and fluid replacement strategy. Erroneous treatment leads to increased morbidity, intensive care admissions, and increased duration of stay [10-11]. Also, inappropriate fluid resuscitation is associated with increased pulmonary complications in COVID-19 [10, 12-13].

Our patient was hypovolemic based on a suggestive history and clinical examination. Hyponatremia workup was sent and fluid replacement was started afterwards awaiting results. The workup showed he was appropriately treated as hypovolemic hyponatremia with IV fluid replacement. Hypovolemic hyponatremia has a higher mortality rate than hyponatremia associated with SIADH [14]. Therefore, caution should be exercised before attributing every hyponatremia in COVID-19 to SIADH. An early clinical judgement should consider the volume status of the COVID-19 patients with hyponatremia to decide between fluid restriction and isotonic fluid replacement.

\section{Conclusions}


Hyponatremia in COVID-19 is not only secondary to SIADH but can also be due to other etiologies. It is critical to establish the cause of hyponatremia early in the disease course to guide initial management. Hypovolemic hyponatremia should be distinguished from SIADH as these conditions employ different management strategies, and the management affects morbidity and mortality.

\section{Additional Information \\ Disclosures}

Human subjects: Consent was obtained by all participants in this study. Conflicts of interest: In compliance with the ICMJE uniform disclosure form, all authors declare the following: Payment/services info: All authors have declared that no financial support was received from any organization for the submitted work. Financial relationships: All authors have declared that they have no financial relationships at present or within the previous three years with any organizations that might have an interest in the submitted work. Other relationships: All authors have declared that there are no other relationships or activities that could appear to have influenced the submitted work.

\section{References}

1. Park SJ, Shin JI: Inflammation and hyponatremia: an underrecognized condition?. Kor J Pediatr. 2013, 56:519-522. 10.3345/kjp.2013.56.12.519

2. Aggarwal S, Garcia-Telles N, Aggarwal G, Lavie C, Lippi G, Michael Henry B: Clinical features, laboratory characteristics, and outcomes of patients hospitalized with coronavirus disease 2019 (COVID- 19): early report from the United States. Diagnosis (Berl). 2020, 2:91-96. 10.1515/dx-2020-0046

3. Berni A, Malandrino D, Parenti G, Maggi M, Poggesi L, Peri A: Hyponatremia, IL-6, and SARS-CoV-2 (COVID-19) infection: may all fit together? J Endocrinol Invest. 2020, 10.1007/s40618-020-01301-W

4. Christ Crain M, Hoorn EJ, Sherlock M, Thompson CJ, Wass JAH: Endocrinology in the time of COVID- 19: management of hyponatraemia and diabetes insipidus. Eur J Endocrinol. 2020, 10.1530/EJE-20-0338

5. Yousaf Z, Al-Shokri SD, Al-soub H, Mohamed MFH: Covid-19 associated SIADH; a clue in the times of pandemic!. Am J Physiol Endocrinol Metab. 2020, 10.1152/ajpendo.00178.2020

6. Ata F, Almasri H, Sajid J, Yousaf Z: COVID-19 presenting with diarrhoea and hyponatraemia. BMJ Case Rep. 2020, 13:e235456.

7. Rondon H, Badireddy M: Hyponatremia. StatPearls Publishing, Treasure Island, FL; 2020.

8. Sharma R, Agarwal M, Gupta M, Somendra S, Saxena SK: Clinical characteristics and differential clinical diagnosis of novel coronavirus disease 2019 (COVID-19). Coronavirus Disease 2019 (COVID-19). 2020 (ed): Springer, Singapore; 2020. 55-70. 10.1007/978-981-15-4814-7 6

9. Lippi G, South AM, Henry BM: Electrolyte imbalances in patients with severe coronavirus disease 2019 (COVID-19). Ann Clin Biochem. 2020, 57:262-265. 10.1177/0004563220922255

10. Corona G, Giuliani C, Parenti G, et al.: Moderate hyponatremia is associated with increased risk of mortality: evidence from a meta-analysis. PLoS One. 2013, 8:e80451. 10.1371/journal.pone.0080451

11. Ahmad K, Alrais ZF, Elkholy HM, et al.: Effect of early correction of hyponatremia on neurological outcome in traumatic brain injury patients. J Intensive Crit Care. 2017, 3:1.

12. Hoorn EJ, Zietse R: Diagnosis and treatment of hyponatremia: compilation of the guidelines . J Am Soc Nephrol. 2017, 28:1340-1349. 10.1681/ASN.2016101139

13. Critical Care [Internet]. Brigham and Women's Hospital COVID-19 Clinical Guidelines . (2020). Accessed: June 6, 2020: http://protocols.netlify.app/protocols/therapeutics/.

14. Cuesta M, Garrahy A, Slattery D, et al.: Mortality rates are lower in SIAD, than in hypervolaemic or hypovolaemic hyponatraemia: results of a prospective observational study. Clin Endocrinol. 2017, 87:400406. 10.1111 /cen.13388 